\title{
A technological overview of cooled radiofrequency ablation and its effectiveness in the management of chronic knee pain
}

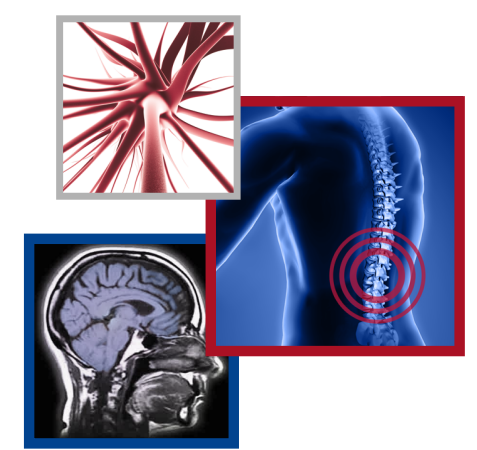

\author{
Leonardo Kapural*,1 \& James P Deering ${ }^{1}$ \\ ${ }^{1}$ Carolinas Pain Institute, 145 Kimel Park Drive, Winston-Salem, NC 27103, USA \\ *Author for correspondence: Ikapuralmd@gmail.com
}

\section{Practice points}

- Cooled radiofrequency ablation is a safe and effective treatment modality in the management of knee osteoarthritis pain.

- Cooled radiofrequency technology imparts distinct physiological differences when compared with standard radiofrequency ablation.

- Heterogeneous patient populations can benefit from cooled radiofrequency ablation treatments.

- Clinical trials have shown pain benefit for patients in 6- and 12-month time periods.

- Repeated cooled radiofrequency ablation provides a similar benefit to an initial denervation.

- In patients who underwent knee replacement, pain relief is of similar degree to those treated for painful osteoarthritis of the knee.

Knee osteoarthritis $(\mathrm{OA})$ is a painful and sometimes debilitating condition affecting an estimated 14 million people in the USA alone. Management of knee OA begins with conservative medical treatments and progresses to total knee arthroplasty. Managing pain until a patient is eligible for arthroplasty remains a key part of the treatment algorithm for knee OA. Cooled radiofrequency ablation has shown clinical effectiveness in managing knee OA pain, with a majority of patients experiencing upwards of 12 months of analgesic effect. Herein is presented an overview of the technology of cooled radiofrequency ablation and a summary of current clinical trials demonstrating the treatments effectiveness.

First draft submitted: 14 December 2019; Accepted for publication: 21 February 2020; Published online: 13 March 2020

Keywords: chronic knee pain $\bullet$ chronic pain $\bullet$ cooled radiofrequency ablation $\bullet$ radiofrequency denervation

Knee osteoarthritis $(\mathrm{OA})$ is a degenerative process causing structural changes within the joint that include a gradual degradation of cartilage. As cartilage degenerates, the protective interface between the distal femur and the proximal tibia is lost, resulting in painful bone-on-bone contact. Knee OA is the most common cause of chronic knee pain with a lifetime prevalence of approximately $45 \%$ [1]. Furthermore, it is a significant source of disability and reduced quality of life $[2,3]$. OA affects an estimated 14 million people in the USA, including nearly 2 million people under the age of 45 years, 6 million between 45 and 64 years, and another 6 million over the age of 65 years [4].

Total knee arthroplasty is an advanced treatment for chronic pain and instability related to OA of the knee. Patients who desire surgery may be deemed poor surgical candidates due to advanced age or complex medical comorbidities [5]. Surgery can be delayed because of a patient's preference, as well as contraindications [6]. Other patients may choose to abstain from surgery because of risks of complications [7]. Arthroplasty implants have an approximate durability of 20 years. Many orthopedic doctors will opt to delay total knee arthroplasty in younger patients in order to avoid complicated revision procedures. Practicing orthopedic surgeons can face difficulties managing painful OA until patients become candidates for surgery.

Several nonsurgical interventions can decrease persistent pain prior to surgery, including weight loss, physical therapy and oral medications. First-line therapy for knee OA is prescription oral nonsteroidal anti-inflammatory drugs (NSAIDs) and acetaminophen, although these can carry gastrointestinal and cardiovascular risks [8]. Patients may then transfer to oral opioid prescriptions, which carry another set of adverse effects, sometimes more serious,

Future Medicine 


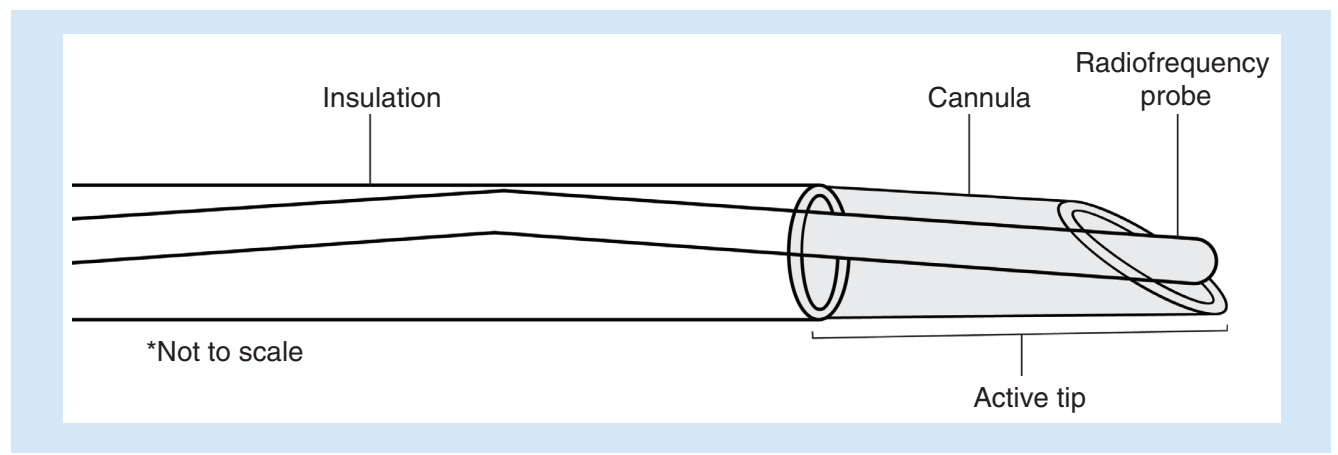

Figure 1. Standard radiofrequency probe.

Adapted with permission from Avanos Medical, Inc.

such as respiratory depression [9]. Eventually, if there is an inadequate therapeutic response to conservative therapy, patients may proceed to more invasive treatments.

Intra-articular steroid injections may provide short-term pain relief from chronic knee pain but may require repeated treatments. In a minority of patients, repeated injections over an extended period of time may cause cartilage damage [10]. Steroid injections may not be the best treatment option for diabetic patients, as they result in elevated blood sugar and metabolic derangements [11].

Hyaluronic acid (HA) injections have been used for years in mild-to-moderate knee OA patients. Hyaluronic acid is thought to delay further cartilage degradation by lubricating and cushioning the joint [12]. However, shortand long-term clinical outcomes of HA therapy varied [13].

Intra-articular platelet-rich plasma therapy, despite world-wide use, suffers from the lack of therapy standardization and very few high-quality randomized prospective trials [14]. Evidence suggests that analgesic effect of platelet-rich plasma injections may be result of other factors, including the placebo effect [15].

Therapeutic approaches that may reduce knee pain and successfully bridge the gap between non-surgical techniques and surgery may provide a significant advancement in patient care. Radiofrequency ablation (RFA) is an attractive option to help patients manage chronic pain from various orthopedic indications. More recently, cooled radiofrequency ablation (CRFA) has emerged as an effective therapy for chronic knee pain. This article serves as an overview of standard RFA as well as CRFA. It will also provide an in-depth review of clinical trials related to CRFA used in the treatment of knee osteoarthritis.

\section{Radiofrequency overview}

Radiofrequency ablation is the process of delivering targeted thermal damage to nearby neural tissue in order to modulate transmission of pain signals. Pain is believed to be attenuated while the body begins to restore the damaged nerve structure.

The radiofrequency probe is a simple electrode structure that generates radiofrequency energy when an electric current is passed through (Figure 1). Radiofrequency probes are able to generate heat in the surrounding tissue through ionic heating. As radiofrequency energy radiates throughout the surrounding tissues, ions $\left(\mathrm{Na}^{+}, \mathrm{K}^{+}\right.$and $\mathrm{Cl}^{-}$) present inside the tissues will oscillate. The friction resulting from the ion movement generates heat, which in turn causes thermal destruction of the nerves.

One important distinction to note is that running an electric current through a radiofrequency probe will not, in and of itself, cause the probe tip to heat. Rather, it is the ionic heating of the surrounding tissue transferring back to the probe tip that is responsible for temperature increases in the probe.

For standard radiofrequency ablation, protocols typically include $90 \mathrm{~s}$ of ionic heating with a target temperature of $80-90^{\circ} \mathrm{C}$. While neural tissue begins to degrade at $43^{\circ} \mathrm{C}$, the target temperature of $80^{\circ} \mathrm{C}$ was informed by in vitro experiments rather than clinical studies. Additionally, the widely adopted goal temperature of $80^{\circ} \mathrm{C}$ is likely related to this being the highest temperature that older radiofrequency (RF) generators and electrodes could consistently attain [16].

A key limitation regarding standard RF techniques relates to the charring of tissues at the electrode interface $[17,18]$. Extended periods of ionic heating will cause desiccation and subsequent charring of the tissues immediately adjacent 


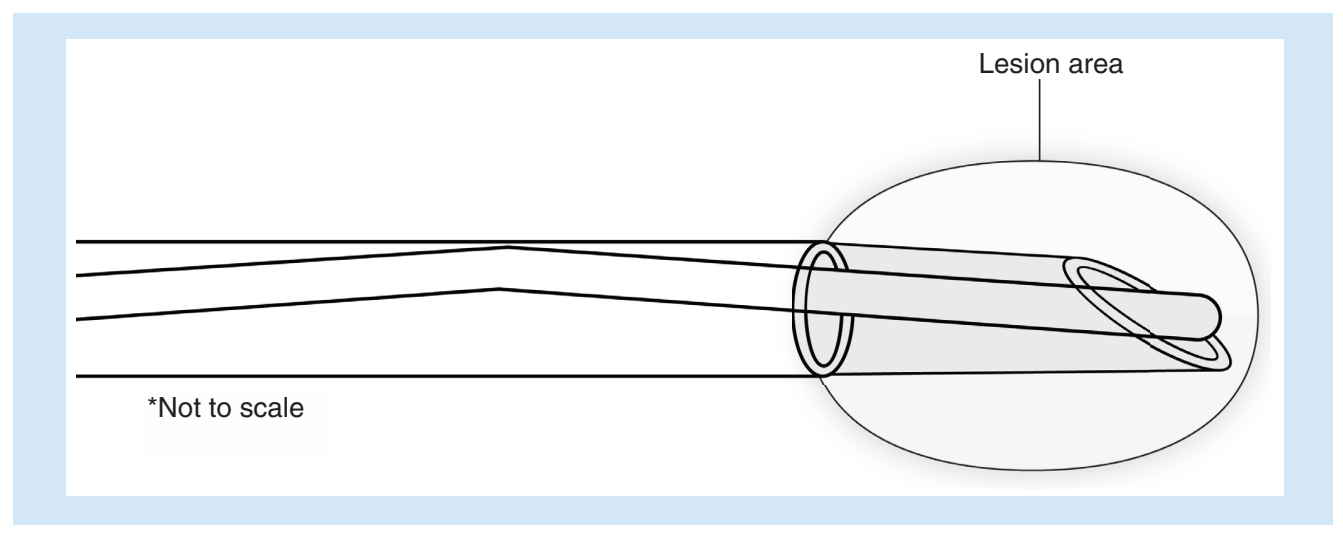

Figure 2. Lesion size and shape created by standard radiofrequency probes. Adapted with permission from Avanos Medical, Inc.

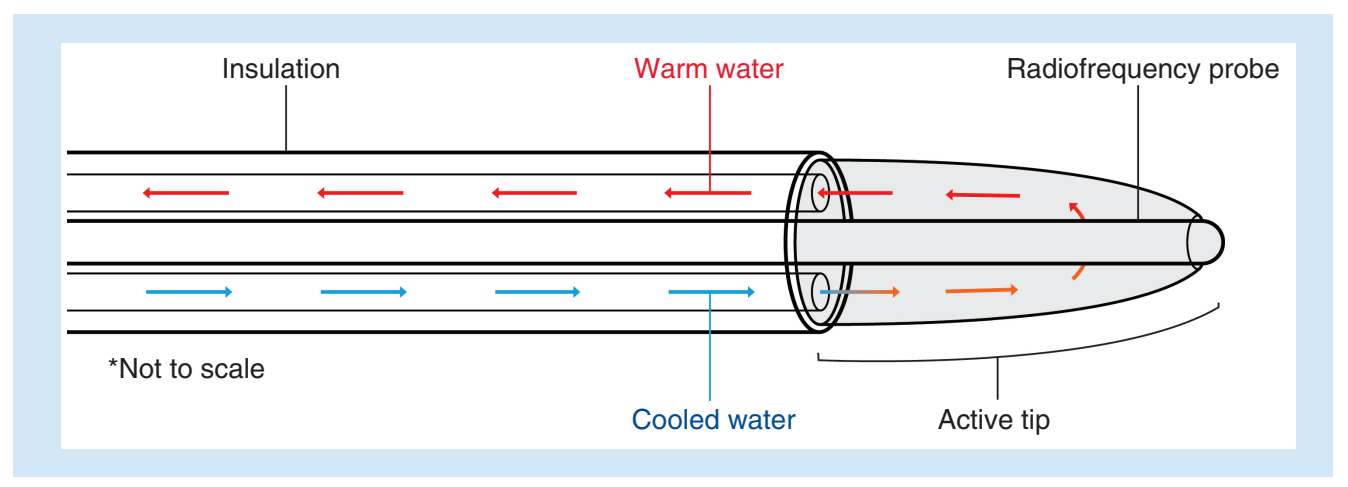

Figure 3. Cooled radiofrequency probe.

Adapted with permission from Avanos Medical, Inc.

to the probe, as this tissue is absorbing the highest concentration of energy. Once the tissue becomes charred, it acts as a significant insulator, preventing any subsequent energy moving beyond the charred tissue, limiting the size of lesions when standard RF technology is used. As such, standard RF lesions are elliptical, as the charring follows the shape of the exposed electrode (Figure 2).

Because of the size and shape limitations associated with standard RF ablation, it can be difficult to reach the desired nerve targets [19]. In order to overcome the charring and subsequent insulation associated with standard RF, cooled radiofrequency probes were developed, whereby cooled water is circulated through the probe tip to maintain lower temperatures at the tissue-tip interface (Figure 3).

The circulated water serves to carry the heat away from the tissue-tip interface, which will reduce the desiccation and subsequent charring of adjacent tissues. As such, CRFA is able to deliver more energy to the surrounding tissues, creating a larger area where ionic heating can occur (Figure 4). While the clinical protocol for CRFA sets the tip temperature at $60^{\circ} \mathrm{C}$, studies have shown that measured temperature beyond the tissue-tip interface reaches $80^{\circ} \mathrm{C}$. Ex vivo studies have demonstrated that mean lesion volume created with CRFA is significantly larger than mean volumes with standard RF ablation [20]. Furthermore, the larger spherical lesion shape can provide more extensive denervation. Larger lesions can reduce the likelihood of missing the target nerve [21-23]. In turn, lesion size may correlate to the degree of pain relief [24].

In addition, recent research suggests that the clinical efficacy of cooled radiofrequency ablation is believed to also be a function of the amount of energy that can be delivered beyond the tissue-tip interface, which can result in a more thorough disruption to the inner nerve structure [25]. This is believed to result in a longer clinical efficacy, as the nerve's ability to transmit pain signals is attenuated while it is healing. 


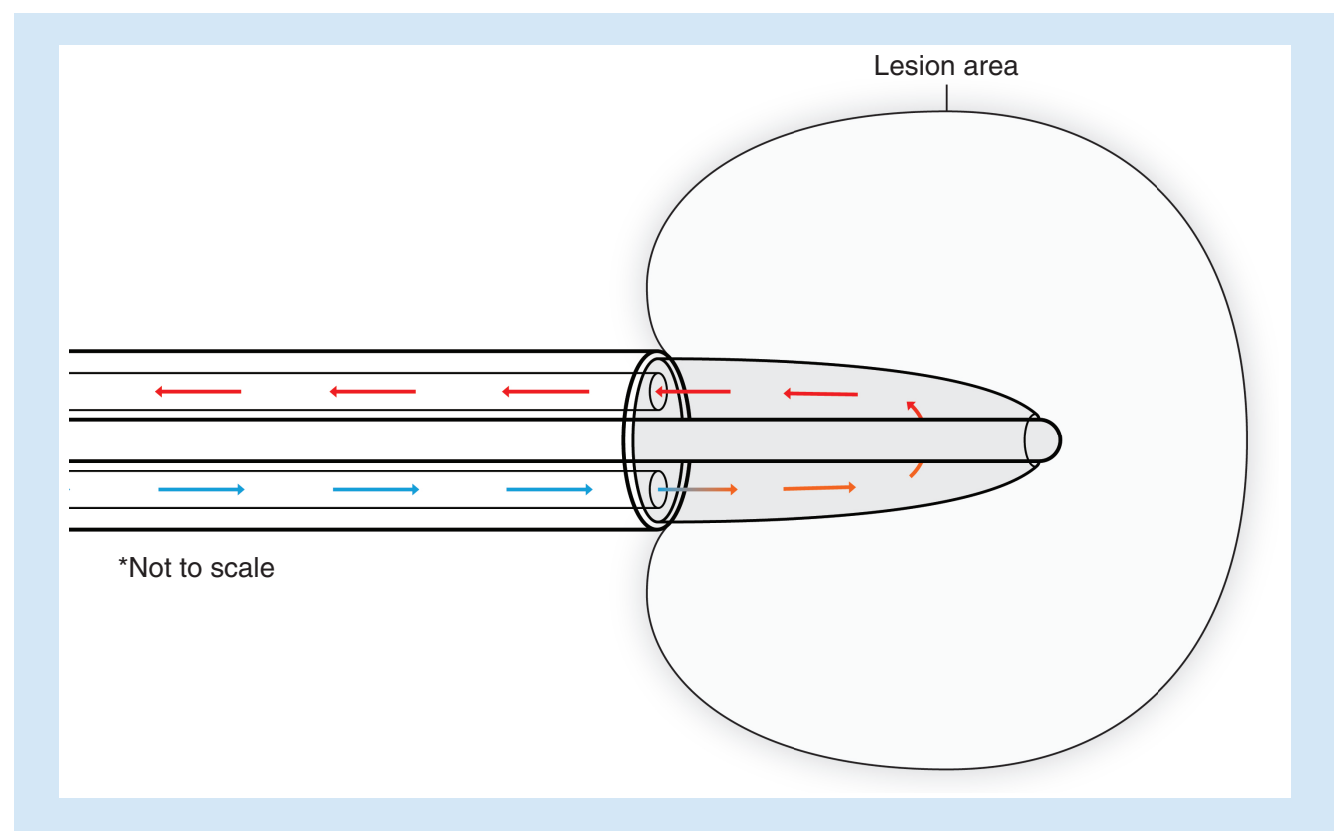

Figure 4. Lesion size and shape created by cooled radiofrequency probes. Adapted with permission from Avanos Medical, Inc.

\section{Clinical benefits of cooled radiofrequency ablation}

A number of clinical trials have demonstrated the efficacy of CRFA in treating OA. Additionally, several trials are underway that compare CRFA to other conservative methods of care.

The first case-series studying clinical effects of CRFA of geniculate nerves to reduce chronic knee OA pain included nine patients [19]. Postprocedure analysis included visual analog scale (VAS) pain scores and Western Ontario McMaster Universities OA index (WOMAC). Baseline VAS scores (mean $8.0 \pm 1.5$ ) decreased significantly (mean VAS score $2 \pm 0.5) 1$ month after the treatment. Long-term patients continued to report a significant pain relief (mean VAS score $2.7 \pm 0.7$ at 3 months, $2.1 \pm 0.5$ at 6 months and $2.2 \pm 0.2$ at 12 months). Baseline WOMAC scores $(88 \pm 1.9)$ also decreased after the first month (mean WOMAC score $20 \pm 2$ ) and follow-up months (mean WOMAC score $22 \pm 0.5$ at 3 months, $21 \pm 1.7$ at 6 months and $20 \pm 1.0$ at 12 months). Therefore, clinical efficacy of CRFA was suggested to extend beyond 1 year after the procedure.

A large, multicenter study followed, comparing efficacy and safety of geniculate nerves CRFA to intra-articular steroid injections in patients with chronic knee pain related to OA [26-28]. A total of 151 subjects unresponsive to conservative modalities were enrolled in this prospective, multicenter, randomized study, and their overall pain and function was assessed at 6 and 12 months using Numeric Rating Scale (NRS), Oxford Knee Score and their own satisfaction (Global Perceived Effect), among other measurements. The primary end point was the proportion of patients whose knee pain was reduced by $50 \%$ or greater from the baseline at 6 months after treatment, with a 12-, 18- and 24-month follow-up to evaluate long-term efficacy.

At 6 months, the CRFA group experienced more favorable pain outcomes in NRS. About $74.1 \%$ of CRFA patients had pain reduction $>50 \%$, compared with only $16.2 \%$ in intra-articular steroid (IAS) group. Mean NRS score reduction was $4.9 \pm 2.4$ (CRFA group) versus $1.3 \pm 2.2$ (IAS group). Mean Oxford Knee Score was $35.7 \pm 8.8$ for subjects receiving CRFA versus $22.4 \pm 8.5$ for those receiving IAS, compared with baseline values of 16.7 and 16.9, respectively. Mean improved Global Perceived Effect was 91.4 versus $23.9 \%$. At 12 months, $65 \%$ of patients in the CRFA group still maintained $\geq 50 \%$ of pain relief, while $75 \%$ were at least somewhat 'improved', suggesting that the pain relief after CRFA can be maintained in the majority of patients for at least 12 months.

Beyond 12 months, a smaller group of patients followed in fewer clinical sites continued to receive benefit from denervation. At 18 months, $12 / 25$ subjects (48.0\%) continue to report $\geq 50 \%$ pain relief. Mean Oxford Knee Score was $47.2 \pm 8.1$ and 20 patients (80.0\%) reported a perceived improvement in their chronic pain condition following a single treatment with CRFA. At 24 months, 11/18 patients reported $\geq 50 \%$ pain relief. Mean Oxford 
Knee Score was $46.8 \pm 10.3$ and 12 patients reported a perceived improvement in their chronic pain condition following a single treatment with CRFA. These data suggest that the benefits of CRFA may extend up to 24 months.

Recently, large real-life retrospective studies have evaluated the long-term pain relief associated with CRFA in knee OA. Kapural et al. studied 275 consecutive patients who had undergone genicular nerve block to determine eligibility for CRFA [29]. Of 205 patients who proceeded to CRFA, 183 (89\%) returned to provide data and 65\% of these patients reported $>50 \%$ pain relief while $77 \%$ had 2 or more VAS points decrease. About $14 \%$ of patients reported no pain at all following CRFA. The mean duration of $>50 \%$ pain relief after CRFA was 12.5 months, suggesting that this technique can provide a significant pain relief well beyond the range of other commonly used minimally invasive modalities $[10,13]$. Patients who underwent a repeated procedure experienced comparable benefit to the benefit received from an initial denervation. Additionally, patients who had already underwent knee arthroplasty prior to CRFA had comparable pain relief obtained from CRFA to patients with painful OA who previously had no knee arthroplasty [29].

Other recent studies have sought to evaluate the efficacy of CRFA compared with other minimally invasive treatment modalities. During one large trial comparing CRFA to viscosupplementation, 179 patients diagnosed with painful knee OA underwent diagnostic geniculate nerve injections [30]. Those who had $\geq 50 \%$ pain relief were randomized to either CRFA of genicular nerves, or a single HA injection. A total of 175 patients were treated $(\mathrm{n}=88 \mathrm{CRFA}$ and $89 \mathrm{HA}$ ) and subsequently evaluated for pain (NRS), function (WOMAC), Global Perceived Effect at 1, 3 and 6 months. A total of 158 patients completed 6 months post treatment $(n=76$ CRFA and 82 HA). In the CRFA group, $71.1 \%$ of patients had $\geq 50 \%$ reduction in NRS pain score compared with $37.8 \%$ in the HA group. The mean NRS was $2.7 \pm 2.3$ for the CRFA group and $4.5 \pm 2.7$ for the HA group. The mean WOMAC score improvement from baseline was $48.2 \%$ in the CRFA group and $22.6 \%$ in the HA group. At 6 months, $72.4 \%$ of patients in the CRFA group reported improvement in Global Perceived Effect compared with $40.2 \%$ in the HA group. CRFA-treated patients demonstrated a significant improvement in pain relief and overall function compared with patients treated with HA.

\section{Patient selection considerations \& predictors of treatment success}

Several studies have investigated whether pain relief following diagnostic nerve block could be a predictor of success for CRFA treatment. McCormick et al. compared subjects reporting $\geq 50 \%$ pain relief for $6 \mathrm{~h}$ following genicular nerve block with local anesthesia ( $1 \mathrm{ml}, 1 \%$ lidocaine) with subjects who did not have $\geq 50 \%$ pain relief [31,32]. The primary outcome measure was the proportion of participants with $\geq 50 \%$ reduction in knee pain at 6 months, as reported by numeric rating scale. Physical function measurements were also collected using the WOMAC. Of those who received and responded to diagnostic block, 58.6\% (17/29) met the primary end point of pain relief. Of those not receiving the diagnostic block, $64.0 \%(16 / 25)$ met the primary end point. While this study demonstrated clinically meaningful improvements in pain relief for both the subject cohorts at 6 -month time point, there was not a correlation between prognostic nerve block and treatment success. The authors note that, in post hoc analysis, when the threshold for selection increases from $\geq 50 \%$ to $\geq 90 \%$ pain relief following prognostic nerve block, increasing subset of patients then experienced successful response to CRFA. The authors suggest that a more stringent prognostic block response may result in substantially higher success rates for CRFA.

In a 2016 case study, Reddy et al. followed four patients who had $\geq 80 \%$ of pain reduction after genicular diagnostic block [33]. After the procedure, all had $>90 \%$ pain reduction at 6 months. All four patients reported 80-100\% improvement in knee pain at 12-months follow-up.

Other factors may influence the outcomes of diagnostic genicular blocks, that include patient selection, fluid volume and anatomical considerations [34,35]. A newer anatomical study of the anterior knee joint capsule showed a complicated frequency map in 15 dissected knees and suggested that the larger lesion may overcome variability of nerve location and possibly influence clinical outcomes [35]. Current research is focused on leveraging a wide range of imaging and electrophysiological techniques, including fluoroscopy, ultrasound and proper sensory testing, to ensure appropriate probe placement.

\section{Conclusion}

In addition to painful OA of the knee, CRFA has also shown durable clinical benefit in spinal indications such as discogenic pain [36-41] and sacroiliac joint pain [42-46]. Cooled radiofrequency technology is able to overcome the physiological shortcomings associated with standard radiofrequency ablation by delivering more energy into the surrounding tissues, which can create both larger lesions as well as more extensively disrupted nerve structures, 
resulting in effective and durable clinical outcomes. Cooled radiofrequency ablation has also demonstrated clinical superiority over the other modalities in the management of chronic knee pain, including intra-articular injections of steroid and hyaluronic acid. A majority of patients with chronic knee pain would experience substantial (>65\%) relief exceeding 12 months, making CRFA an attractive modality for long-term management of pain associated with knee OA. Similar levels of pain relief have been consistently achieved with repeat CRFA when compared with pain relief from a patient's first CRFA [29], assuring that consistent long-term CRFA therapy can be maintained.

\section{Future perspective}

While CRFA for chronic knee pain seems to be largely successful, additional optimization of this therapy based on newly acquired knowledge on anatomy, optimal imaging, stimulating patterns and patient selection may provide even better outcomes and benefit a larger population of patients. More studies are needed to evaluate outcomes of CRFA in patients with other causes of chronic knee pain, as well as those who maintain their chronic knee pain after the knee replacement.

Author contributions

L Kapural drafted this manuscript. JP Deering contributed to the writing of the original manuscript.

\section{Acknowledgments}

E Moorhead (Avanos Medical) assisted in the drafting and image development for this manuscript.

\section{Financial \& competing interests disclosure}

L Kapural is a paid consultant (Scientific Advisory Board) for Avanos Medical, Abbott and Medtronic. The authors have no other relevant affiliations or financial involvement with any organization or entity with a financial interest in or financial conflict with the subject matter or materials discussed in the manuscript apart from those disclosed.

No writing assistance was utilized in the production of this manuscript.

\section{References}

Papers of special note have been highlighted as: $\bullet$ of interest

1. Murphy L, Schwartz TA, Helmick CG et al. Lifetime risk of symptomatic knee osteoarthritis. Arthritis Rheum. 59(9), 1207-1213 (2008).

2. Mannoni A, Briganti MP, di Bari M et al. Epidemiological profile of symptomatic osteoarthritis in older adults: a population based study in Dicomano, Italy. Ann. Rheum. Dis. 62(6), 576-578 (2003).

3. Michael JW, Schlüter-Brust KU, Eysel P. The epidemiology, etiology, diagnosis, and treatment of osteoarthritis of the knee. Dtsch Arztebl Int. 107(9), 152-162 (2010).

4. Deshpande BR, Katz JN, Solomon DH, Yelin EH, Hunter DJ. Number of persons with symptomatic knee osteoarthritis in the US: impact of race and ethnicity, age, sex, and obesity. Arthritis Care Res. 68, 1743-1750 (2016).

5. Samson AJ, Mercer GE, Campbell DG. Total knee replacement in the morbidly obese: a literature review. ANZ J. Surg. 80(9), 595-599 (2010).

6. Bruyere $\mathrm{O}$, Cooper C, Pelletier JP et al. A consensus statement on the European society for clinical and economic aspects of osteoporosis and osteoarthritis (ESCEO) algorithm for the management of knee osteoarthritis - from evidence-based medicine to the real-life setting. Semin. Arthritis Rheum. 45, S3-S11 (2016).

7. Luzzi AJ, Fleischman AN, Matthews CN, Crizer MP, Wilsman J, Parvizi J. The 'Bundle Busters': incidence and costs of postacute complications following total joint arthroplasty. J. Arthroplasty 33(9), 2734-2739 (2018).

8. Pelletier J-P, Martel-Pelletier J, Rannou F, Cooper C. Efficacy and safety of oral NSAIDs and analgesics in the management of osteoarthritis: evidence from real-life setting trials and surveys. Semin. Arthritis Rheum. 45, S22-S27 (2016).

9. Fuggle N, Curtis E, Shaw $S$ et al. Safety of opioids in osteoarthritis: outcomes of a systematic review and meta-analysis. Drugs Aging 36(S1), 129-143 (2019).

10. Raunauld J, Buckland-Wright C, Ward R et al. Safety and efficacy of long-term intraarticular steroid injections in osteoarthritis of the knee: a randomized, double-blind, placebo-controlled trial. Arthritis Rheum. 48, 370-377 (2003).

11. Habib GS, Miari W. The effect of intra-articular triamcinolone preparations on blood glucose levels in diabetic patients: a controlled study. J. Clin. Rheum. 17, 302-305 (2011).

12. Altman RD, Manjoo A, Fierlinger A et al. The mechanism of action for hyaluronic acid treatment in the osteoarthritic knee: a systematic review. BMC Musculoskelet. Disord.16, 321 (2015).

13. Bowman S, Awad ME, Hamrick MW, Hunter M, Fulzele S. Recent advances in hyaluronic acid based therapy for osteoarthritis. Clin. Transl. Med. 7(1), 6 (2018). 
14. Gato-Calvo L, Magalhaes J, Ruiz-Romero C, Blanco FJ, Burguera EF. Platelet-rich plasma in osteoarthritis treatment: review of current evidence. Ther. Adv. Chronic Dis. 10, 1-18 (2019).

15. Jones IA, Togashi R, Wilson ML, Heckmann N, Vangsness CT. Intra-articular treatment options for knee osteoarthritis. Nat. Rev. Rheum. 15(2), 77-90 (2019).

16. Ball RD. The science of conventional and water-cooled monopolar lumbar radiofrequency rhizotomy: an electrical engineering point of view. Pain Physician 38, E175-E211 (2014).

- An overview of the physics behind both standard and cooled radiofrequency probes.

17. Nath S, DiMarco JP, Haines DE. Basic aspects of radiofrequency catheter ablation. J. Cardiovasc. Electrophysiol. 5, $863-876$ (1994).

18. Haines DE, Verow AF. Observations on electrode-tissue interface temperature and effect on electrical impedance during radiofrequency ablation of ventricular myocardium. Circulation 82, 1034-1038 (1990).

19. Bellini M, Barbieri M. Cooled radiofrequency system relieves chronic knee osteoarthritis pain: the first case-series. Anaesthesiol. Intensive Ther. 47(1), 30-33 (2015).

- The first case series demonstrating the use of cooled radiofrequency ablation (CRFA) in the management of knee pain related to osteoarthritis (OA).

20. Cedeño DL, Vallejo A, Kelley CA, Tilley DM, Kumar N. Comparisons of lesion volumes and shapes produced by a radiofrequency system with a cooled, a protruding, or a monopolar probe. Pain Physician 8, E915-E922 (2017).

21. Bogduk N. Practice Guidelines for Spinal Diagnostic and Treatment Procedures. International Spine Intervention Society, CA, USA (2004).

22. Lord SM, McDonald GJ, Bogduk N. Review article: percutaneous radiofrequency neurotomy of the cervical medial branches $-\mathrm{a}$ validated treatment for cervical zygapophysial joint pain. Neurosurg. Q. 8, 288-308 (1998).

23. Govind J, King W, Bailey B, Bogduk N. Radiofrequency neurotomy for the treatment of third occipital headache. J. Neurol. Neurosurg. Psychiatry 74(1), 88-93 (2003).

24. Cosman ER, Dolensky JR, Hoffman RA. Factors that affect radiofrequency heat lesion size. Pain Med. 15(12), 2020-2036 (2014).

25. English A, Provenzano D, Adesina $S$ et al. Cooled RF ablation produces enhanced thermal lesions and greater reduction in nerve function. Presented at: ASRA 17th Annual Pain Medicine Meeting. TX,

USA, (2018). https://epostersonline.com/ASRAFALL18/node/761?view=true

26. Davis T, Loudermilk E, DePalma M et al. Prospective, multicenter, randomized, crossover clinical trial comparing the safety and effectiveness of cooled radiofrequency ablation with corticosteroid injection in the management of knee pain from osteoarthritis. Reg. Anesth. Pain Med. 43(1), 84-91 (2018).

- The 6-month results of a large, randomized, multicenter clinical trial comparing CRFA to steroid injections for the management of knee OA pain.

27. Davis T, Loudermilk E, DePalma M et al. Twelve-month analgesia and rescue, by cooled radiofrequency ablation treatment of osteoarthritic knee pain: results from a prospective, multicenter, randomized, cross-over trial. Reg. Anesth. Pain Med. 44(4), 499-506 (2019).

- The 12-month results of a large, randomized, multicenter clinical trial comparing CRFA to steroid injections for the management of knee OA pain.

28. Hunter C, Davis T, Loudermilk E, Kapural L, DePalma M. Cooled radiofrequency ablation treatment of the genicular nerves in the treatment of osteoarthritic knee pain: 18 and 24-month results. Pain Pract. 20(3), 238-246 (2019).

The 18- and 24-month results of a large, randomized, multicenter clinical trial comparing CRFA to steroid injections for the management of knee OA pain.

29. Kapural L, Lee N, Neal K, Burchell M. Long-term retrospective assessment of clinical efficacy of radiofrequency ablation of the knee using a cooled radiofrequency system. Pain Physician 22, 489-494 (2019).

30. Chen AF, Khalouf F, Zora $\mathrm{K}$ et al. Cooled radiofrequency ablation demonstrates greater efficacy and equivalent safety compared to a single injection of hyaluronic acid for chronic knee pain management: a multi-center, randomized, clinical trial. J. Bone Joint Surg. (2019) (In Press).

- The 6-month results of a large, randomized, multicenter clinical trial comparing CRFA to hyaluronic acid injections for the management of knee OA pain.

31. McCormick ZL, Korn M, Reddy R et al. Cooled radiofrequency ablation of the genicular nerves for chronic pain due to knee osteoarthritis: six-month outcomes. Pain Med. 18(9), 1631-1641 (2017).

32. McCormick ZL, Korn M, Reddy R et al. A prospective randomized trial of prognostic genicular nerve blocks to determine the predictive value for the outcome of cooled radiofrequency ablation for chronic knee pain due to osteoarthritis. Pain Med. 19(8), 1628-1638 (2018).

33. Reddy RD, McCormick ZL, Marshall B, Mattie R, Walega DR. Cooled radiofrequency ablation of genicular nerves for knee osteoarthritis pain: a protocol for patient selection and case series. Anesth. Pain Med. 6(6), e39696 (2016).

34. Oladeji L, Cook J. Cooled radio frequency ablation for the treatment of osteoarthritis-related knee pain: evidence, indications, and outcomes. J. Knee Surg. 32(1), 65-71 (2019). 
35. Tran J, Peng PWH, Lam K, Baig E, Agur AMR, Gofeld M. Anatomical study of the innervation of anterior knee joint capsule: implication for image-guided intervention. Reg. Anesth. Pain Med. 43(4), 407-414 (2018).

36. Karaman H, Tüfek A, Kavak GÖ et al. 6-month results of transdiscal biacuplasty on patients with discogenic low back pain: preliminary findings. Int. J. Med. Sci. 8(1), 1-8 (2011).

37. Kapural L, Vrooman B, Sarwar S et al. A randomized, placebo-controlled trial of transdiscal radiofrequency, biacuplasty for treatment of discogenic lower back pain. Pain Med. 14(3), 362-373 (2013).

38. Kapural L, Mekhail N. Novel intradiscal biacuplasty (IDB) for the treatment of lumbar discogenic pain. Pain Pract. 7(2), 130-134 (2007).

39. Desai MJ, Kapural L, Petersohn JD et al. A prospective, randomized, multicenter, open-label clinical trial comparing intradiscal biacuplasty to conventional medical management for discogenic lumbar back pain. Spine 41(13), 1065-1074 (2016).

40. Desai MJ, Kapural L, Petersohn JD et al. Twelve-month follow-up of a randomized clinical trial comparing intradiscal biacuplasty to conventional medical management for discogenic lumbar back pain. Pain Med. 18, 751-763 (2016)

41. Helm S, Simopoulos TT, Stojanovic M, Abdi S, Terany MAE. Effectiveness of thermal annular procedures in treating discogenic low back pain. Pain Physician 20(6), 447-470 (2017).

42. Cohen SP, Hurley RW, Buckenmaier CC, Kurihara C, Morlando B, Dragovich A. Randomized placebo-controlled study evaluating lateral branch radiofrequency denervation for sacroiliac joint pain. Anesthesiology 109(2), 279-288 (2008).

43. Patel N. Twelve-month follow-up of a randomized trial assessing cooled radiofrequency denervation as a treatment for sacroiliac region pain. Pain Practice 16(2), 154-167 (2016).

44. Ho K, Hadi MA, Pasutharnchat K, Tan K-H. Cooled radiofrequency denervation for treatment of sacroiliac joint pain: two-year results from 20 cases. J. Pain Res. 6, 505-511 (2013).

45. Tinnirello A, Barbieri S, Todeschini M, Marchesini M. Conventional (Simplicity III) and cooled (SInergy) radiofrequency for sacroiliac joint denervation: one-year retrospective study comparing two devices. Pain Med. 18(9), 1731-1744 (2017).

46. Sun HH, Zhuang SY, Hong X, Xie XH, Zhu L, Wu XT. The efficacy and safety of using cooled radiofrequency in treating chronic sacroiliac joint pain: a PRISMA-compliant meta-analysis. Medicine 97(6), e9809 (2018). 